\title{
An Examination of Third-Party Disapproval in Intercultural Couples
}

\section{MELANIE CHRISTOFOROU}

Department of Psychology, University of Toronto Scarborough, Canada

\section{Abstract}

Intercultural couples tend to experience a unique set of challenges, such as disapproval from close social networks. This disapproval has been associated with decreased commitment and uncertainty within couples, leading to issues of trust between partners. However, the influence of third-party disapproval affects a romantic couple differently depending on the source of the disapproval. Few studies have examined and compared the individual influences of family and friend disapproval on romantic relationships, and even less have researched these effects on intercultural dating couples. We used archival data from 63 heterosexual intercultural couples to examine the separate influences of family and friend disapproval on romantic investment while controlling for trust, which is a key factor in successful romantic relationships. As predicted, the results of the ActorPartner Interdependence Model (APIM) analyses demonstrated that family and friend disapproval negatively affected one's investment in their relationship. Mediation analyses revealed that trust only mediated the correlation between friend disapproval and relationship investment, and not that of family disapproval and relationship investment.

Keywords: intercultural couples, third-party disapproval, investment

\section{Introduction}

Relationships do not exist in isolation, or within a social vacuum. Rather, they are embedded within our social networks. One's social networks can have multifaceted effects on the stability and quality of romantic relationships (Felmlee, 2001; Felmlee et al., 1990), particularly for intercultural couples

(Sung, 1990). Intercultural dyads, which contain partners of different cultural values, as well as ethnic, racial, or religious backgrounds, tend to experience a unique set of challenges. Compared to intracultural couples, which are comprised of partners from the same culture, intercultural couples experience challenges such as third-party disapproval significantly more (Skowroński et al., 2014). The influence of third-party disapproval, however, affects romantic couples differently depending on the source of the disapproval (e.g., friends or family) (Skowroński et al., 2014). That is, 
disapproval from close friends predicts greater relationship demise and dissatisfaction, along with increased anxiety and lower relationship gratification, eventually leading to the demise of the relationship (Etcheverry et al., 2008; Felmlee, 2001; Wright \& Sinclair, 2012), whereas parental disapproval has been shown to predict lower relationship quality as well as greater instability and relationship dissolution (Felmlee, 2001; Sung, 1990; Wright \& Sinclair, 2012).

While there is a consensus across the literature that social network disapproval negatively affects romantic relationships (Felmlee, 2001; Sinclair et al., 2014), most of the literature either examines only one influence (e.g., friends or family) or aggregates close family and friend opinions rather than examining and comparing each source. This study will be examining the individual effects of family and close friend disapproval on one's willingness to invest in their intercultural romantic relationship.

\section{The Influence of Third-Party Disapproval on Investment}

Third-party disapproval is one of the largest impediments to intercultural couples, significantly impacting the couple's ability to succeed and navigate through all challenges and stages of the dyadic cycle (Skowroński et al., 2014; Molina et al., 2004). For decades, researchers have attributed these obstacles to the social network effect. This effect suggests that disapproval from close family and friends serves to dissuade the couple by discouraging the relationship, consequently increasing negative relationship outcomes (Sinclair et al., 2014). As a result, couples who experience third-party disapproval are often found to be at greater risk of failure due to a lack of commitment, greater instability, and a greater decline in the quality of the relationship (Skowroński et al., 2014). Such negative responses place considerable anxiety and apprehension on intercultural couples, consequently, making it more difficult for one to want to invest in their romantic relationship (Molina et al., 2004).

Relationship investment, as defined by Rusbult (1983), refers to one's willingness to invest in their romantic relationship while considering how satisfied they are with their relationship, the quality of their available alternatives, and how committed they are to their romantic partner (Rusbult, 1983). Studies have shown that support from family and close friends predicts relationship persistence, reducing the likelihood of relationship termination (Felmlee et al., 1990). In contrast, close social network disapproval decreases the intimacy, closeness, and stability of dating couples (Parks et al., 1991).

Similarly, when examining intercultural married couples in the United States, 
Hohmann-Marriott \& Amato (2008) found that diminished support from family members decreased the quality of the relationship, which lead to a decline in relationship investment (HohmannMarriott \& Amato, 2008). In addition, Betty Lee Sung (1990) who examined intercultural married couples, found that greater family disapproval not only led to fierce conflicts, which resulted in secret dating, unpleasant family events, and feelings of guilt, but that disapproval also placed great strain on the couple. Under debilitating circumstances such as these, it can become challenging and arduous for intercultural dyads to remain satisfied in their relationship, making it even more effortful to remain committed and willing to invest in that relationship.

Past research investigating the effects of third-party disapproval on intercultural couples have primarily focused on intermarriage couples and have found, in general, that greater disapproval from social networks results in negative relationship outcomes (Hohmann-Marriott \& Amato, 2008; Sung, 1990). These studies, however, have excluded examining key relationship factors such as respect and honesty as mediators in terms of disapproval and dyadic investment. Researchers have identified trust as a critical component for successful relationships, observing that perceptions of trust from one's partner tend to lead to increased investment in their romantic relationships (Wieselquist et al., 1999,
Driscoll et al., 1972). Therefore, this study will be examining trust as a mediator between third-party disapproval and investment.

\section{The Influence of Third-Party Disapproval On Trust}

Disapproval from close family and friends can contribute largely to the demise of one's relationship in the form of decreased investment (Wright \& Sinclair, 2012). Likewise, third-party disapproval can also contribute to the collapse of one's relationship in the form of trust (Parks \& Adelman, 1983). As described by Rempel and colleagues (1985), trust refers to feeling confident and secure in the strength of one's relationship and in one's partner to respond in a caring and supportive manner (Rempel et al., 1985). For couples, Larzelere \& Huston (1980) suggest that trust acts to reinsure and increase security in one's relationship, in turn reducing apprehension and inhibitions so that one can be free to share and be open with their partner (Larzelere \& Huston, 1980). However, given that intercultural dyads experience greater disapproval than intracultural couples (Sung 1990), reducing one's trepidation is made difficult when disapproval creates increased feelings of reservation and doubt about one's partner and relationship (Graham et al., 1985).

Studies examining intercultural couples have found family disapproval to 
negatively affect how much one trusts their partner (Fontaine \& Dorch, 1980; Parks \& Adelman, 1983). Researchers have also found relationship uncertainty to be the underpinning of dyadic turbulence (Solomon \& Knobloch, 2001). In contrast, couples who had received support from their close social networks had been found to experience less uncertainty about their romantic relationship and partner, as well as experience a decline in the likelihood of a breakup (Parks and Adelman, 1983). This demonstrates that the greater the disapproval from close family and friends, the more uncertain one is about their relationship and partner (Parks \& Adelman, 1983). Without certainty in one's relationship, partners cannot trust their significant other and are therefore unable to build the foundational stability needed to handle difficult situations as a unit.

While the majority of these studies do not indicate if the participants recruited were involved in intercultural rather than intracultural relationships, we can posit that the results for intercultural couples would be similar if not worse than what has been demonstrated in the previous findings. Given that intercultural couples report more severe problems with close family and friends (Fontaine \& Dorch, 1980), specifically in the form of disapproval, it can be postulated that opposition, whether from close family or friends, would have severe ramifications on an intercultural couple's level of trust.

\section{The Influence of Trust on Investment} Trust

Trust is an exceptionally important factor in determining how much one is willing to invest in their romantic relationship (Rempel et al., 2001). For instance, as couples develop increased trust, both partners are likely to become progressively more reliant on each other, increasing their commitment to the relationship and forgoing alternatives (Wieselquist et al., 1999). While examining the relationship between commitment and trust, Wieselquist and colleagues (1999) found that a partner's trust is significantly positively associated with the other partner's level of commitment to the relationship, in that trust acts as a gauge for determining how committed one's partner is to the relationship (Wieselquist et al., 1999).

Furthermore, studies that have examined intercultural couples have found trust to be positively associated with commitment, in that those who have greater trust in their romantic partners are considerably more committed to their romantic relationships and have greater relationship well-being and stability (Blair and Holmberg, 2008). This demonstrates that the support, or lack thereof, of close support networks, not only relates to one's level of trust in their partner and relationship but it also contributes to one's willingness to invest in their romantic relationship. 


\section{Overview of the Current Study}

Although previous studies have examined the effects of social networks and thirdparty disapproval on romantic relationship outcomes, several gaps remain in the literature. First, the majority of past literature has examined romantic couples in general, not specifically the experiences of intercultural dating couples. Second, most of the literature examining thirdparty disapproval has aggregated both family and friend disapproval to observe social networks as a whole. The current study, by comparison, examined both family and friend disapproval distinctly to gain a more in-depth and comparative understanding of the separate influences of close family and friend disapproval on intercultural dyads. Third, while studies have examined the relationships between disapproval, investment, and trust distinctly, no study has yet examined how all three are associated together, particularly in intercultural couples. Therefore, we proposed trust as a mediator of the association between third-party disapproval and investment in intercultural romantic relationships.

Specifically, this study examined four hypotheses. First, we predicted that family and friend disapproval, independently, are significantly related to one's willingness to invest in their relationship, where greater disapproval would lead one's level of romantic investment to decrease. Second, based on the consistency of negative relationship outcomes caused by social network disapproval, we postulated that family and friend disapproval, independently, are significantly related to how much one trusts their partner. Third, we hypothesized that how much one trusts their partner is significantly related to one's willingness to invest in their relationship, whereby greater trust in one's partner will increase romantic investment. Fourth, family disapproval and relationship investment will be mediated by trust, as will friend disapproval and investment, meaning that the relationship between close family and friend disapproval and one's willingness to invest in their relationship will be explained by how much one trusts their romantic partner.

\section{Methods}

We conducted secondary data analyses on archived data originally collected by Dr. SiSi Tran from the University of Toronto Scarborough. The methods used during original recruitment are described below. To be eligible, couples must have met the following criteria: (1) be in a heterosexual dating relationship of at least six months, (2) contain two romantic partners of different (a) cultural values, practices, traditions, or ideologies, (b) ethnic backgrounds, (c) racial backgrounds, or (d) religious backgrounds, and (3) both partners are able to participate in the study. No exclusions were made, thus the study. No exclusions were made, thus the 
sample used for our analyses included all 63 heterosexual intercultural couples $(N=$ 126 individuals; mean age $=20.78$ years, SD age $=3.52$ years) from the original data collection. The majority of participants (27.8\%) were of East Asian ethnicity. 26.2\% were North American, $22.2 \%$ were South Asian, $7.9 \%$ were European, $4.8 \%$ were Caribbean, $4.8 \%$ were South American, $3.2 \%$ were Middle Eastern, and $3.2 \%$ were African. Participants were recruited from first-year undergraduate psychology courses at the University of Toronto Scarborough via SONA.

Participants were first asked to complete a packet of questionnaires pertaining to their thoughts and feelings regarding their relationship, partner, and self. The current study examined the responses to a Thirdparty Disapproval single-item question, "My family disapproves of our relationship" and "My friends disapprove of our relationship", where participants responded on a 5 -point likert scale, 1 (They approve) to 5 (They do not approve), along with two questionnaires. The first questionnaire examined was The Trust Scale (Rempel, Holmes, \& Zanna, 1985). Participants' responses on this questionnaire were used to assess one's level of trust in their partner within close interpersonal relationships. Questions such as, "I can rely on my partner to keep the promises he/she makes to me" and "My partner behaves in a very consistent manner", were answered on a 7-point likert scale, 1 (I strongly disagree) to 7 (I strongly agree). The Investment model by Rusbult (1983) was the second questionnaire examined. It measured relationship investment and other important factors of relationship quality. Questions such as, "How much longer do you want your current relationship to last?", "Do you feel satisfied with your current relationship?", were answered using a 9-point likert scale. Specifically, we examined the aggregated scores of all subscales for each questionnaire to gain a more holistic score for trust and investment. Additional questionnaires were included during the initial data collection but were not pertinent to the present study and will not be discussed further.

IBM SPSS Statistics 23 software was used to conduct descriptive statistics, correlations, and regression analyses. Due to the dyadic nature of the data, mediation models were tested using Actor-Partner Interdependence Modeling (APIM) via Multiple Linear Regression analyses. APIM allows for tests of actor and partner effects, such that all tests of actor effects (e.g., Person A's trust in his/her partner predicting Person A's willingness to invest in the relationship) simultaneously control for partner effects (e.g., Partner B's trust predicting Partner A's willingness to invest). Before testing the hypotheses for this study, Pearson's correlations ( $r$ ) were calculated to assess the strength, direction, and significance between all major variables. The largest acceptable 
alpha used to determine statistical significance was $p<0.05$.

\section{Results}

The correlations across family disapproval, friend disapproval, trust, and investment are presented for both actor (Person A) and partner (Person B) in Table 1. While both actor and partner correlations are reported, actor effect scores were used explicitly for the mediation models.

As seen in Figures 1 and 2, both family disapproval $\left(R^{2}=.26, F_{(4,121)}=10.73, p\right.$ $\left.<.05 ; \beta=-.22, t_{(123)}=-2.41, p<.05\right)$ and friend disapproval $\left(R^{2}=.09, F_{(2,123)}=\right.$ $5.72, p<.01 ; \beta=-.27, t_{(123)}=-2.81, p<$ $.01)$, were found to have a negative effect on investment as well as trust. Although the results showed a non-significant association between family disapproval and trust (Figure $1 ; R^{2}=.68, F_{(2,123)}=$ $4.51, p<.01 ; \beta=-.15, t_{(123)}=-1.60, p=$ .11), the relationship between friend disapproval and trust revealed a significantly strong negative association (Figure $2 ; R^{2}=.16, F_{(2,123)}=11.97, p<$ $\left..001 ; \beta=-.35, t_{(123)}=-3.83, p<.001\right)$. After controlling for family disapproval, trust was a significant predictor of investment $\left(R^{2}=.26, F_{(4,121)}=10.73, p<.001 ; \beta=.39\right.$, $\left.t_{(121)}=-4.83, p<.001\right)$ similarly for when controlling for friend disapproval $\left(R^{2}=.24\right.$, $F_{(4,121)}=9.46, p<.001 ; \beta=.40, t_{(121)}=$ $-1.25, p<.001)$.

When controlling for trust, the association between family disapproval and investment became marginally significant $\left(R^{2}=.26, F_{(4,121)}=10.72, p<.10 ; \beta=-.14\right.$, $\left.t_{(121)}=-1.71, p<.10\right)$ albeit not significantly so (Sobel's $z=-1.51, p=.13$ ). In turn, the relationship between friend disapproval and investment became nonsignificant when controlling for trust $\left(R^{2}=\right.$ $.24, F_{(4,121)}=9.46, p<.01 ; \beta=-.12, t_{(121)}=$ -1.25, $p=.22$ ), indicating that the relationship between friend disapproval and investment is explained by trust (Sobel's $z=-2.94, p<.01$ ).

Table 1. Correlations Across All Major Variables.

${ }^{* * *} p<.001 .{ }^{* *} p<.01 .{ }^{*} p<.05$.

\begin{tabular}{|l|c|c|c|c|c|c|c|c|}
\hline \multicolumn{1}{|c|}{ Variables } & $\mathbf{1}$ & $\mathbf{2}$ & $\mathbf{3}$ & $\mathbf{4}$ & $\mathbf{5}$ & $\mathbf{6}$ & $\mathbf{7}$ & $\mathbf{8}$ \\
\hline 1. Actor Family Disapproval & - & & & & & & & \\
\hline 2. Actor Friend Disapproval & $.39^{* *}$ & - & & & & & & \\
\hline 3. Actor Trust & $-.20^{*}$ & $-.40^{* *}$ & - & & & & & \\
\hline 4. Actor Investment & $-.27^{* *}$ & $-.29^{* *}$ & $.46^{* *}$ & - & & & & \\
\hline $\begin{array}{l}\text { 5. Partner Family } \\
\text { Disapproval }\end{array}$ & $.33^{* *}$ & $.24^{* *}$ & $-.22^{*}$ & $-.24^{* *}$ & - & & & \\
\hline $\begin{array}{l}\text { 6. Partner Friend } \\
\text { Disapproval }\end{array}$ & $.24^{* *}$ & $.44^{* *}$ & $-.25^{* *}$ & -.16 & $.39^{* *}$ & - & & \\
\hline 7. Partner Trust & $-.22^{*}$ & $-.25^{* *}$ & .18 & $.21^{*}$ & $-.20^{*}$ & $-.40^{* *}$ & - & \\
\hline 8. Partner Investment & $-.20^{*}$ & -.11 & .16 & $.26^{* *}$ & $-.25^{* *}$ & $-.25^{* *}$ & $.37^{* *}$ & - \\
\hline
\end{tabular}




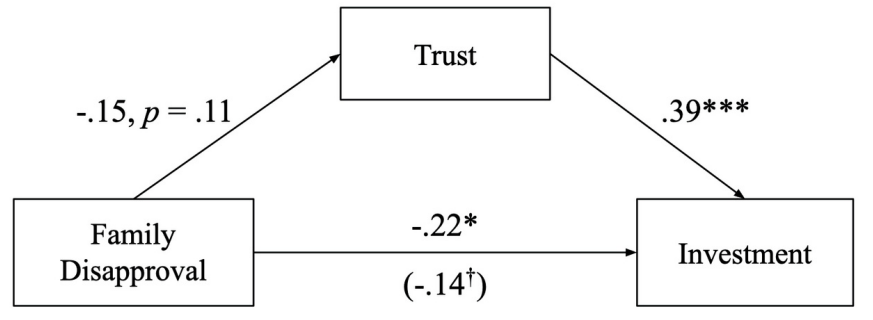

Sobel's z $=-1.51, p=.13$

Figure 1. Multiple regression coefficients for the relationship between actor family disapproval and actor investment as mediated by actor trust.

The standardized regression coefficient between actor family disapproval and actor investment, controlling for actor trust, is in parentheses. ${ }^{* * *} p<$ $.001,{ }^{* *} p<.01,{ }^{*} p<.05, \dagger p<.10$.

\section{Discussion}

The present study examined the relationship between third-party disapproval (i.e., friends and family) and relationship investment as mediated by trust among intercultural couples. Unlike previous studies, we examined close family and close friend disapproval as separate influencers to gain a more indepth understanding of the individual weight that each source of support has on romantic relationship investment.

Consistent with prior research, in general, both family and friend disapproval were found to be similarly negatively associated with investment. However, a closer examination revealed the role of trust towards one's partner in mediating the relationship

between third-party disapproval and investment, differed depending on the source of the disapproval. Unexpectedly, trust did not

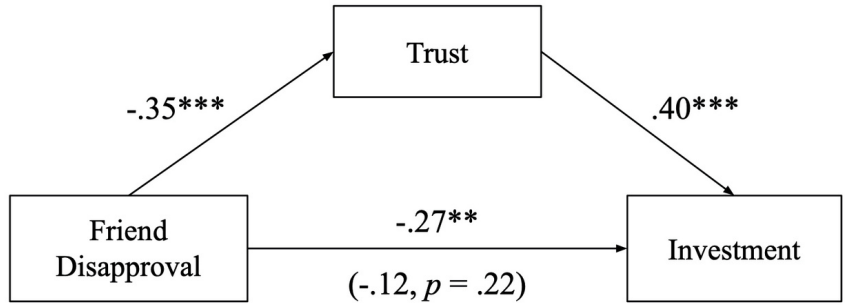

Sobel's $\mathrm{z}=-2.94, p<.01$

Figure 2. Multiple regression coefficients for the relationship between actor friend disapproval and actor investment as mediated by actor trust.

The standardized regression coefficient between actor friend disapproval and actor investment, controlling for actor trust, is in parentheses. ${ }^{* * *} p<$ $.001,{ }^{* *} p<.01,{ }^{*} p<.05, \dagger p<.10$.

significantly mediate the relationship between family disapproval and investment. However, trust for one's partner significantly mediated the association between friend disapproval with investment: higher friend disapproval predicted lower trust in their romantic partner which, in turn, predicted lower investment in the relationship. This suggests that friend disapproval is perhaps more closely related to investment in intercultural couples through the trust participants have in their partner than originally determined in past literature (Leslie et al., 1986; Wright \& Sinclair, 2012). One reason for this could be due to the different structural connections seen in parent-child relationships compared to friendships (Wright \& Sinclair, 2012). That is, parental relationships are not chosen, they are hierarchical and permanent, making them reliable and consistent, whereas friendships are voluntary, egalitarian, and typically temporary 
(Wright \& Sinclair, 2012). Moreover, friendships are much more fragile compared to parent-child relationships, which are considerably more stable, secure, and consistent. Therefore, one may be more inclined to end a romantic relationship that their friends did not approve of in order to appease that friendship. This may be especially true for intercultural relationships where friends were seen, in our results, to be a stronger negative source on one's relationship. In this case, trust would have a more meaningful role in the relationship between friend disapproval and investment than it does for family disapproval and investment, as a more fragile relationship requires trust to prosper.

While friend disapproval was negatively associated with how much one trusted their partner, the relationship between family disapproval and trust was not significant. This is contrary to previous research on intercultural couples which demonstrated that family disapproval negatively affected how much one trusts their romantic partner (Fontaine \& Dorch, 1980; Parks \& Adelman, 1983). Perhaps the stronger association between friends' disapproval and trust could be attributed to the various stages of one's relationship. Results from past literature have found that young adults tend to monitor the amount of information they tell their family about their romantic partners, such that the more committed the individual was to their dating partner, the more likely they were to notify the family of their relationship (Leslie et al., 1986). Given the scrutiny that many intercultural couples experience from close family, it is plausible that they would wait until the relationship was more serious before introducing their partner to their family. Perhaps by waiting their trust in their partner may be more solidified and less vulnerable to external influences, such as family disapproval. This is a possible explanation for our findings as the majority of couples in this study were dating $(81.7 \%)$, in contrast to the $18.3 \%$ who were married or engaged. Many of the couples in this study had only been dating for a duration of 6 months.

One limitation of this current research is that it was conducted with only an undergraduate sample. Although past research has also used undergraduate samples (Etcheverry et al., 2008; Lehmiller \& Agnew, 2007), the younger sample could be a possible contributor to our findings. Specifically, friends are much more salient and present in universities compared to parents, especially if the student is living away from home while attending school. Therefore, examining the unique association of close family and friend disapproval on investment in various age cohorts would be a beneficial goal for future research. For instance, it would be intriguing to examine how the effects of third-party disapproval for dating couples in their late twenties or early thirties 
differ from that of university students in their late teens and early twenties. Moreover, it would be interesting to examine if there is a shift in how influential one type of disapproval is to another and the potential motivations behind those shifts depending on age, or in this instance, depending on how prominent one's friends or family are in one's life.

Although this work aimed to extend previous research by specifically examining intercultural couples, our research only examined heterosexual couples and we cannot conclude whether these findings would be generalizable to other types of couples. Thus, future researchers should diversify their work to include intercultural same-sex dating couples to gain a more in-depth understanding of disapproval in various relationship types. Future investigations should also extend this work by examining the effects of third-party disapproval on other essential relationship factors such as partner respect, understanding, and honesty in intercultural couples as this could provide researchers with greater insight into other romantic relationship processes.

\section{Conclusion}

Intercultural couples are becoming increasingly more common in today's society. Therefore, it is essential that we expand the previous research which has focused predominantly on intracultural romantic relationships. The current work extended previous research on third-party disapproval by examining both family and friend disapproval as independent predictors on relationship investment to understand the unique relationship that each source has on intercultural dyads. Further, we examined actor effects while controlling for one's partner.

By conducting more studies like this present one, researchers can further add to the limited literature on intercultural romantic relationships as well as illuminate our understanding of additional important relationship factors in the various contexts of romantic relationships.

\section{Acknowledgements}

I would like to express my sincere gratitude and thank Dr. SiSi Tran for all of her assistance and support with this study. 


\section{References}

Blair, K. L., \& Holmberg, D. (2008). Perceived social network support and well-being in same-sex versus mixed-sex romantic relationships. Journal of Social and Personal Relationships, 25(5), 769-791. https://doi.org/10.1177/0265407508096695

Driscoll, R., Davis, K. E., \& Lipetz, M. E. (1972). Parental interference and romantic love: The Romeo and Juliet effect. Journal of Personality and Social Psychology, 24(1), 1-10. https://doi.org/10.1037/h0033373

Etcheverry, P. E., Le, B., \& Charania, M. R. (2008). Perceived versus reported social referent approval and romantic relationship commitment and persistence. Personal Relationships, 15(3), 281-295. https://doi.org/10.1111/j.1475-6811.2008.00199.x

Felmlee, D., Sprecher, S., \& Bassin, E. (1990). The dissolution of intimate relationships: A hazard model. Social Psychology Quarterly, 13-30. https://doi.org/10.2307/2786866

Felmlee, D. H. (2001). No couple is an island: A social network perspective on dyadic stability. Social Forces, 79(4), 1259-1287. https://www.jstor.org/stable/2675472

Fontaine, G., \& Dorch, E. (1980). Problems and benefits of close intercultural relationships. International Journal of Intercultural Relations, 4(3-4), 329-337. https://doi.org/10.1016/0147-1767(80)90008-5

Graham, M. A., Moeai, J., \& Shizuru, L. S. (1985). Intercultural marriages: An intrareligious perspective. International Journal of Intercultural Relations, 9(4), 427-434. https://doi.org/10.1016/0147-1767(85)90059-8

Hohmann-Marriott, B. E., \& Amato, P. (2008). Relationship quality in interethnic marriages and cohabitations. Social Forces, 87(2), 825-855. https://www.jstor.org/stable/20430893

Joel, S., Gordon, A. M., Impett, E. A., MacDonald, G., \& Keltner, D. (2013). The things you do for me: Perceptions of a romantic partner's investments promote gratitude and commitment. Personality and Social Psychology Bulletin, 39(10), 1333-1345. https://doi.org/10.1177/0146167213497801

Kline, S. L., Horton, B., \& Zhang, S. (2008). Communicating love: Comparisons between American and East Asian university students. International Journal of Intercultural Relations, 32(3), 200-214. https://doi.org/10.1016/j.ijintrel.2008.01.006 
Larzelere, R. E., \& Huston, T. L. (1980). The dyadic trust scale: Toward understanding interpersonal trust in close relationships. Journal of Marriage and Family, 595-604. https://doi.org/10.2307/351903

Lehmiller, J. J., \& Agnew, C. R. (2007). Perceived marginalization and the prediction of romantic relationship stability. Journal of Marriage and Family, 69(4), 1036-1049. https://doi.org/10.1111/j.1741-3737.2007.00429.x

Leslie, L. A., Huston, T. L., \& Johnson, M. P. (1986). Parental reactions to dating relationships: Do they make a difference? Journal of Marriage and Family, 48(1), 57-66. https://doi.org/10.2307/352228

Molina, B., Estrada, D., \& Burnett, J. A. (2004). Cultural communities: Challenges and opportunities in the creation of "happily ever after" stories of intercultural couplehood. The Family Journal, 12(2), 139-147. https://doi.org/10.1177/1066480703261962

Parks, M. R., \& Adelman, M. B. (1983). Communication networks and the development of romantic relationships: An expansion of uncertainty reduction theory. Human Communication Research, 10(1), 55-79. https://doi.org/10.1111/j.14682958.1983.tb00004.x

Parks, M. R., \& Eggert, L. L. (1991). The role of social context in the dynamics of personal relationships. In W. H. Jones \& D. Perlman (Eds.), Advances in personal relationships. Advances in personal relationships: A research annual, Vol. 2 (p. 1-34). Jessica Kingsley Publishers.

Rempel, J. K., Holmes, J. G., \& Zanna, M. P. (1985). Trust in close relationships. Journal of Personality and Social Psychology, 49(1), 95-1. https://doi.org/10.1037/0022-3514.49.1.95

Rempel, J. K., Ross, M., \& Holmes, J. G. (2001). Trust and communicated attributions in close relationships. Journal of Personality and Social Psychology, 81(1), 57-64. https://doi.org/10.1037/0022-3514.81.1.57

Rusbult, C. E. (1983). A longitudinal test of the investment model: The development (and deterioration) of satisfaction and commitment in heterosexual involvements. Journal of Personality and Social Psychology, 45(1), 101-117. https://doi.org/10.1037/00223514.45.1.101 
Sinclair, H. C., Hood, K. B., \& Wright, B. L. (2014). Revisiting the Romeo and Juliet effect (Driscoll, Davis, \& Lipetz, 1972): Reexamining the links between social network opinions and romantic relationship outcomes. Social Psychology, 45(3), 170-178, http://dx.doi.org/10.1027/1864-9335/a000181

Skowroński, D. P., Othman, A. B., Siang, D. T. W., Han, G. L. W., Yang, J. W. J., \& Waszyńska, K. (2014). The outline of selected marital satisfaction factors in the intercultural couples based on the Westerner and non-Westerner relationships. Polish Psychological Bulletin, 45(3), 346-356. https://doi.org/10.2478/ppb-2014-0042

Solomon, D. H., \& Knobloch, L. K. (2001). Relationship uncertainty, partner interference, and intimacy within dating relationships. Journal of Social and Personal Relationships, 18(6), 804-820. https://doi.org/10.1177/0265407501186004

Sung, B. L. (1990). Chinese American intermarriage. Journal of Comparative Family Studies, 21(3), 337-352. https://doi.org/10.3138/jcfs.21.3.337

Wieselquist, J., Rusbult, C. E., Foster, C. A., \& Agnew, C. R. (1999). Commitment, prorelationship behavior, and trust in close relationships. Journal of Personality and Social Psychology, 77(5), 942-966. https://doi.org/10.1037/0022-3514.77.5.942

Wright, B. L., \& Sinclair, H. C. (2012). Pulling the strings: Effects of friend and parent opinions on dating choices. Personal Relationships, 19(4), 743-758. https://doi.org/10.1111/j.1475-6811.2011.01390.x 